\title{
Market Timing and Security Market Line Analysis
}

\author{
ALEXANDER KEMPF and KLAUS KREUZBERG*
}

August 8, 2003

\begin{abstract}
It seems to be widely accepted that Jensen alpha fails to detect successful market timing funds spuriously indicating poor fund performance. Jensen (1972), Admati and Ross (1985), Dybvig and Ross (1985), and Grinblatt and Titman (1989), (1995) attribute that to an upwards biased estimate of the systematic risk of successful market timers. Therefore, they recommend not to use alpha in external performance evaluation. In this paper, we show that this conclusion is misleading. We set up a theory of delegated portfolio management in a mean variance framework with asymmetric information. Within this model we prove that alpha is an unbiased performance measure even for market timing funds. We show that the systematic risk for a fund investor consists of two parts: benchmark risk and management risk resulting from the uncertainty about the skills of the fund manager. We show that the extent of management risk depends on what fund investors know about the fund manager's trade record. Therefore, the performance of mutual funds depends not only on the skills of the fund managers, but also on whether they publish their trade record or not.

(JEL classification: G11, G23).
\end{abstract}

${ }^{*}$ We are grateful to Olaf Korn, Christoph Memmel, and Eric Theissen for their helpful comments. Both authors are from the University of Cologne, Department of Finance, Albertus-Magnus-Platz, 50923 Köln, Germany, www.wiso.uni-koeln.de/finanzierung. Phone: +49-221-4702714, Fax: +49-221-4703992, Email: kempf@wiso.uni-koeln.de, kreuzberg@wiso.uni-koeln.de. 


\section{Introduction}

The measurement of the performance of mutual funds is an important issue for both investment companies and fund investors. Investment companies pay fund managers partly based on their performance [e.g. Admati and Pfleiderer (1997), Coles, Suay, and Woodbury (2000)] and mutual fund investors chase fund performance [e.g. Patel, Zeckhauser, and Hendricks (1990), Ippolito (1992), Gruber (1996)]. Whereas investment companies can judge the skills of a fund manager by observing her trade record, fund investors typically do not have access to this information. They only observe the record of the net asset value of a fund.

Most empirical studies on mutual fund performance use the information set of a fund investor and estimate fund performance based on time series data of net asset value. The classical performance measures are Jensen (1968), Sharpe (1966), and Treynor (1965). Although widely used to test for superior information of mutual fund managers, these measures are originally based on the CAPM which does not account for informational asymmetry. This gave rise to plenty of controversy about whether the measures are appropriate for external performance evaluation. Jensen (1972), Admati and Ross (1985), Dybvig and Ross (1985) and Grinblatt and Titman (1989) argue that uninformed fund investors using these measure do not correctly classify informed fund managers as outperforming. Admati and Ross (1985) and Dybvig and Ross (1985) show that they occasionally assign a negative performance to fund managers who choose portfolios which are optimized with respect to their superior private beliefs. Grinblatt and Titman (1989) attribute this result to an overassessment of the systematic risk of successful market timers. Since fund managers seem to have market timing skills [e.g. Ippolito (1989), Bollen and Busse (2001), Chance and Hemler (2001)], one has to conclude that the classical performance measures are inappropriate for external performance evaluation. Subsequently, Grinblatt and Titman (1993), Daniel, Grinblatt, Titman, and Wermers (1997), 
Wermers (2000) suggested performance measures which overcome the drawbacks of the classical measures by focusing on fund holdings instead of fund returns. However, these holdings based measures require the knowledge of the fund holdings and can be typically used only for internal performance evaluation. Therefore, it is an open question which performance measure can be used for external performance evaluation, i.e. for investors not observing fund holdings.

In our paper we question the common view that Jensen alpha is inappropriate for external performance evaluation. We provide a theory of delegated portfolio management that recognizes the link between fund management skills, informational asymmetries, and mutual fund performance. The key contribution of our paper is to show that the risk associated with a state contingent ("active") mutual fund portfolio depends not only on the average risk level chosen by the fund manager, but also on the information fund investors have about the portfolio strategy. If the fund investors cannot observe managerial holdings, they bear the additional risk about what the manager effectively does. Therefore, two fund investors with different information sets bear different amounts of risk investing in the same fund. The optimal fund trading strategy differs for the two investors and, ultimately, those two investors rightly assign different performances to the same fund.

Since the Jensen alpha is an external performance measure we apply it for fund investors who cannot observe the fund holdings. We show that the Jensen alpha is an unbiased performance measure in the notion of Dybvig and Ross (1985) for those uninformed fund investors. (i) A fund manager without private information plots on the security market line. (ii) The performance of a fund manager with superior market timing information is positive provided optimal fund behaviour. In this case, (iii) the performance of a fund manager is additionally the higher the better the managerial signal is.

The results of our paper have three main implications: First, the Jensen measure can be used 
for external performance evaluation. Second, fund managers deciding on the fund portfolio have to incorporate what their investors know about fund holdings. Third, mutual funds can increase their performance not only by doing a good research, but also by providing sufficient information to their clients. The information policy of a fund matters.

The schedule of our paper is as follows. Section II briefly reviews the critique on the Jensen alpha. In Section III we set up our model and derive efficient fund trading strategies. In Section IV we show that the Jensen measure is unbiased given that (i) fund investors are uninformed and (ii) fund managers act in the interests of their clients. We demonstrate that the bias-in-beta component of the Jensen measure reported by Grinblatt and Titman (1989) represents a risk premium for management risk. Section $\mathrm{V}$ concludes.

\section{Market Timing and Performance Bias}

In this section we briefly review the critique against the classical performance measures. We outline the arguments using Jensen alpha as the performance measure, but the arguments apply to other performance measures as well. For sake of clarity, we focus on a pure market timing fund. We use a model similar to Grinblatt and Titman (1989) $]^{1}$ The random fund excess return, $\tilde{R}_{P}$, is determined by the benchmark excess return, $\tilde{R}_{E}$, and the fraction of the fund portfolio invested in the benchmark asset, $\tilde{w}_{P}$.

$$
\tilde{R}_{P}=\tilde{w}_{P} \tilde{R}_{E}
$$

\footnotetext{
${ }^{1}$ Grinblatt and Titman (1989) use large sample estimates of the parameters $\mathrm{E}\left[\tilde{R}_{P}\right], \mathrm{E}\left[\tilde{R}_{E}\right]$, and $\beta_{P}$ in their analysis. Since OLS estimation yields asymptotically unbiased estimates of these parameters [e.g. Grant (1977)], the arguments in the remainder of the paper can be equivalently based on the large sample estimates or on the true parameter values. We choose the latter throughout our analysis.
} 
We assume the benchmark asset to be mean variance efficient with respect to public information and to offer a positive risk premium $\left(\mathrm{E}\left[\tilde{R}_{E}\right]>0\right)$. Since the fund manager is a market timer, her benchmark holding is random and correlated with the benchmark return, i.e. $\operatorname{cov}\left(\tilde{w}_{P}, \tilde{R}_{E}\right) \neq 0$

Jensen (1968) defines mutual fund performance by the deviation of the expected fund excess return, $\mathrm{E}\left[\tilde{R}_{P}\right]$, from the security market line $(\mathrm{SML}), \beta_{P} \mathrm{E}\left[\tilde{R}_{E}\right]$ :

$$
\begin{aligned}
J_{P} & =\mathrm{E}\left[\tilde{R}_{P}\right]-\beta_{P} \mathrm{E}\left[\tilde{R}_{E}\right], \\
\text { with } \beta_{P} & =\frac{\operatorname{cov}\left(\tilde{R}_{P}, \tilde{R}_{E}\right)}{\operatorname{var}\left(\tilde{R}_{E}\right)}
\end{aligned}
$$

Assuming no fund fees and transaction costs, all portfolios based on public information plot on the SML. Deviations from the SML occur only if the portfolio manager has private information [Mayers and Rice (1979)]. Positive deviations indicate managerial skills.

Grinblatt and Titman (1989) argue that successful market timers might plot below the SML spuriously indicating poor fund management. They demonstrate this result by decomposing the expected fund excess return, $\mathrm{E}\left[\tilde{R}_{P}\right]$, into its determinants: the expected excess return $\mathrm{E}\left[\tilde{w}_{P}\right] \mathrm{E}\left[\tilde{R}_{E}\right]$ of a portfolio with weights identical to the average fund holdings, $\mathrm{E}\left[\tilde{w}_{P}\right]$, and the expected return component due to market timing, $\left.\mathrm{E}\left[\tilde{R}_{P}^{T}\right]\right|^{2}$

$$
\begin{aligned}
\mathrm{E}\left[\tilde{R}_{P}\right] & =\mathrm{E}\left[\tilde{w}_{P}\right] \mathrm{E}\left[\tilde{R}_{E}\right]+\mathrm{E}\left[\tilde{R}_{P}^{T}\right] \\
\text { with } \tilde{R}_{P}^{T} & =\left(\tilde{w}_{P}-\mathrm{E}\left[\tilde{w}_{P}\right]\right) \tilde{R}_{E}
\end{aligned}
$$

\footnotetext{
${ }^{2}$ See Eq. 3 of Grinblatt and Titman (1989). In the decomposition of Grinblatt and Titman (1989) the expected return due to stock picking shows up as a third term. Here, this term is zero since we concentrate on pure market timing funds.
} 
Substituting (4) into (2) demonstrates that the performance measure of Jensen for a pure market timer consists of two parts:

$$
J_{P}=\mathrm{E}\left[\tilde{R}_{P}^{T}\right]-\left(\beta_{P}-\mathrm{E}\left[\tilde{w}_{P}\right]\right) \mathrm{E}\left[\tilde{R}_{E}\right]
$$

Grinblatt and Titman argue that only the first component in (6) measures the correct performance of a market timing fund and propose their timing measure:

$$
J_{P}^{\text {Timing }}=E\left[\tilde{R}_{P}^{T}\right]
$$

They attribute the second component in (6) to a bias-in-beta which occurs if one applies the Jensen measure to market timing funds. Grinblatt and Titman show that the bias-in-beta term is negative for a pure market timer, i.e. fund investors seem to overestimate the benchmark exposure $\left(\beta_{P}>\mathrm{E}\left[\tilde{w}_{P}\right]\right)$. It might even happen that the Jensen measure $(6)$ is negative for a market timer with superior information. Grinblatt and Titman demonstrate that external fund investors (not knowing the fund holdings) are not able to identify the two components in (6) separately. They conclude that the Jensen measure is biased for external performance evaluation because it misjudges market timers to be poor performers. Similar conclusions are drawn by Jensen (1972), Admati and Ross (1985) and Dybvig and Ross (1985).

We will question this conclusion in the remainder of the paper. We will show that the arguments outlined above are based on an inefficient fund strategy. Assuming efficient managerial behaviour, we will prove that (i) the Jensen measure is unbiased and (ii) the second component in (6) is not a bias, but a risk premium. 


\section{Efficient Fund Portfolios}

In this section we derive mutual fund trading rules which are efficient for fund investors. We show that the set of efficient fund portfolios depends not only on the information set of the fund manager, but also on the information set of the fund investor. In Subsection A we present a model of delegated portfolio management. In Subsection B we derive efficient fund portfolios given that fund investors know the fund holdings. In Subsection C we derive efficient fund portfolios given that fund investors do not know the fund holdings. In Subsection $\mathrm{D}$ we compare the two sets of efficient fund portfolios and prove that they mutually exclude each other.

\section{A. Model Setup}

Consider a fund manager $(P)$ who receives a noisy signal, $\tilde{m}_{P}$, about the excess return of the benchmark. Given this signal, the excess return of the benchmark asset is

$$
\tilde{R}_{E}=\mathrm{E}\left[\tilde{R}_{E}\right]+\tilde{m}_{P}+\tilde{\gamma}_{P}
$$

where $\tilde{\gamma}_{P}$ is a noise term. $\tilde{m}_{P}$ and $\tilde{\gamma}_{P}$ are assumed to be independently and normally distributed with zero mean and variances $\operatorname{var}\left(\tilde{m}_{P}\right)>0$ and $\operatorname{var}\left(\tilde{\gamma}_{P}\right)>0$, respectively. The fund manager uses her signal for market timing. She trades on her conditional beliefs about the benchmark excess return:

$$
\tilde{R}_{E} \mid m_{P} \sim N\left(\mathrm{E}\left[\tilde{R}_{E}\right]+m_{P}, \operatorname{var}\left(\tilde{\gamma}_{P}\right)\right)
$$


We assume that the fund market consists of a large number of uninformed funds so that the market share of informed funds is negligible. Therefore, the trading of informed funds has no impact on the benchmark return. This view of the fund market is taken from Mayers and Rice (1979). It has several important implications: (i) An informed fund manager can exploit her private information without mitigating it. (ii) Fund investors cannot infer the private information of informed fund managers from observable benchmark return. (iii) Fund investors assign to each fund a zero ex-ante probability of being an informed fund. We further assume that fund investors have no own private signal about the benchmark return, but know only the unconditional benchmark return distribution:

$$
\tilde{R}_{E} \sim N\left(\mathrm{E}\left[\tilde{R}_{E}\right], \operatorname{var}\left(\tilde{m}_{P}\right)+\operatorname{var}\left(\tilde{\gamma}_{P}\right)\right)
$$

In addition, fund investors might observe the fund holdings. We denote the information set of a fund investor by $\theta$. Fund investors are risk averse (with $\lambda>0$ as parameter of risk aversion) and look for a fund which optimizes the tradeoff between their conditionally expected fund return and fund risk:

$$
\Phi=\mathrm{E}\left[\tilde{R}_{P} \mid \theta\right]-\frac{\lambda}{2} \operatorname{var}\left(\tilde{R}_{P} \mid \theta\right)
$$

The assumption of mean variance preferences is taken to obtain analytical results. It should be noted that (11) is a limitation of our analysis. Although the return of the benchmark is normal, the fund return is not normally distributed due to the randomness of the fund holdings. Therefore, the preference function (11) is not equivalent to a more general expected utility function. 
We assume that there are no agency conflicts between fund managers and fund investors. Therefore, the fund manager chooses the portfolio, $w\left(m_{P}\right)$, which maximizes the preference function (11) of the fund investor. Using (1) we can rewrite (11) as:

$$
\Phi=\mathrm{E}\left[w\left(\tilde{m}_{P}\right) \tilde{R}_{E} \mid \theta\right]-\frac{\lambda}{2} \operatorname{var}\left(w\left(\tilde{m}_{P}\right) \tilde{R}_{E} \mid \theta\right)
$$

The portfolio problem in (12) reflects the basic concept of mutual fund management: A fund manager uses all her private information, $\tilde{m}_{P}$, but chooses the fund portfolio, $w\left(\tilde{m}_{P}\right)$, such that it is optimal for the fund investors. Therefore, the optimal trading rule depends not only on the market timing signal of the manager, but also on the information $\theta$ available to the fund investors. To obtain tractable results we restrict our analysis to linear market timing rules, $w\left(\tilde{m}_{P}\right)=a_{P}+b_{P} \tilde{m}_{P}$.

Since fund investors might differ with respect to their risk aversion $\lambda$, we will not focus on a single optimal portfolio, but on the set of efficient fund portfolios. For this purpose, we use the following definition of fund portfolio efficiency under asymmetric information: A fund portfolio $w\left(\tilde{m}_{P}\right)$ is said to be mean variance efficient for investors with information set $\theta$, if there exists a parameter of risk aversion $\lambda>0$ such that $w\left(\tilde{m}_{P}\right)$ for this investor is the optimal portfolio among those using the signal $\tilde{m}_{P}$. This notion of portfolio efficiency is a generalization of the well known definition of mean variance efficiency in models with homogeneous information. It should be noted that the set of efficient portfolios (using the signal $\tilde{m}_{P}$ ) depends here on the private information of the fund manager and on the information of the fund investors about fund holdings. In the remainder of this section we will show how the set of efficient portfolios depends on the amount of holdings information the fund provides to the fund investors. 


\section{B. Informed Investors}

If fund investors know the fund holdings $\left(\theta=\left\{w_{I}\right\}\right)$, the optimization problem of the fund manager (12) can be written as:

$$
\Phi_{I}=w_{I}\left(m_{P}\right) \mathrm{E}\left[\tilde{R}_{E} \mid w_{I}\right]-\frac{\lambda}{2} w_{I}^{2}\left(m_{P}\right) \operatorname{var}\left(\tilde{R}_{E} \mid w_{I}\right)
$$

The moments of the benchmark return distribution are now conditional on the known fund holdings. In Appendix A we show that those conditional moments are given as:

$$
\begin{aligned}
\mathrm{E}\left[\tilde{R}_{E} \mid w_{I}\right] & =\mu_{E}+\tilde{m}_{P} \\
\operatorname{var}\left(\tilde{R}_{E} \mid w_{I}\right) & =\operatorname{var}\left(\tilde{\gamma}_{P}\right)
\end{aligned}
$$

Maximization of (13) then implies for the optimal trading rule of the fund manager:

$$
w_{I}^{*}\left(\tilde{m}_{P}\right)=\frac{\mathrm{E}\left[\tilde{R}_{E}\right]+\tilde{m}_{P}}{\lambda \operatorname{var}\left(\tilde{\gamma}_{P}\right)}
$$

Note that informed fund investors can infer the private information of the fund manager by observing the fund holdings. Therefore, publishing the portfolio holdings is equivalent to publishing the signal. There is no information asymmetry between fund manager and fund investors. Varying $\lambda$ in (16) leads to the set of efficient fund portfolios:

$$
\Lambda_{I}=\left\{w_{I}^{*}\left(\tilde{m}_{P}\right)=\frac{\mathrm{E}\left[\tilde{R}_{E}\right]+\tilde{m}_{P}}{\lambda \operatorname{var}\left(\tilde{\gamma}_{P}\right)}: \lambda>0\right\}
$$




\section{Uninformed Investors}

We now turn to the case that fund investors have no access to the fund holdings. This is the typical situation for most fund investors. In this case, a fund investor knows only the unconditional distribution of the benchmark return and (13) can be rewritten as:

$$
\begin{aligned}
\Phi_{U} & =\mathrm{E}\left[\tilde{R}_{P}\right]-\frac{\lambda}{2} \operatorname{var}\left(\tilde{R}_{P}\right) \\
& =\mathrm{E}\left[w_{U}\left(\tilde{m}_{P}\right) \mathrm{E}\left[\tilde{R}_{E} \mid \tilde{m}_{P}\right]\right]-\frac{\lambda}{2}\left\{\mathrm{E}\left[w_{U}\left(\tilde{m}_{P}\right)^{2} \operatorname{var}\left(\tilde{R}_{E} \mid \tilde{m}_{P}\right)\right]+\operatorname{var}\left(w_{U}\left(\tilde{m}_{P}\right) \mathrm{E}\left[\tilde{R}_{E} \mid \tilde{m}_{P}\right]\right)\right\}
\end{aligned}
$$

The fund manager has to choose the trading rule such that she exploits here private information in an optimal way, but has to keep in mind that the fund investors only know the unconditional moments of the return distribution. The optimal trading rule is shown in Appendix $B$ to be:

$$
w_{U}^{*}\left(\tilde{m}_{P}\right)=\frac{\left(\mathrm{E}\left[\tilde{R}_{E}\right]+\tilde{m}_{P}\right)\left(\operatorname{var}\left(\tilde{R}_{E}\right)-\mathrm{E}\left[\tilde{R}_{E}\right]^{2}\right)+2 \mathrm{E}\left[\tilde{R}_{E}\right]^{3}}{\lambda\left\{\operatorname{var}\left(\tilde{\gamma}_{P}\right)\left(\operatorname{var}\left(\tilde{R}_{E}\right)+\mathrm{E}\left[\tilde{R}_{E}\right]^{2}+2 \operatorname{var}\left(\tilde{m}_{P}\right)\right)+2 \operatorname{var}\left(\tilde{m}_{P}\right)^{2}\right\}}
$$

If fund investors have no holdings information, the optimal trading rule (19) depends not only on the parameters of the conditional benchmark return distribution of the fund manager, $\mathrm{E}\left[\tilde{R}_{E}\right]+m_{P}$ and $\operatorname{var}\left(\tilde{\gamma}_{P}\right)$, but also on $\operatorname{var}\left(\tilde{m}_{P}\right)$. Since uninformed investors cannot identify the dynamics of the fund holdings, they bear additional risk about whether the fund manager is an informed manager. $\operatorname{var}\left(\tilde{m}_{P}\right)$ accounts for this management risk. Varying $\lambda$ in $(19)$ leads to the set of efficient trading rules given that investors are uninformed:

$$
\Lambda_{U}=\left\{w_{U}^{*}\left(\tilde{m}_{P}\right)=\frac{\left(\mathrm{E}\left[\tilde{R}_{E}\right]+\tilde{m}_{P}\right)\left(\operatorname{var}\left(\tilde{R}_{E}\right)-\mathrm{E}\left[\tilde{R}_{E}\right]^{2}\right)+2 \mathrm{E}\left[\tilde{R}_{E}\right]^{3}}{\lambda\left\{\operatorname{var}\left(\tilde{\gamma}_{P}\right)\left(\operatorname{var}\left(\tilde{R}_{E}\right)+\mathrm{E}\left[\tilde{R}_{E}\right]^{2}+2 \operatorname{var}\left(\tilde{m}_{P}\right)\right)+2 \operatorname{var}\left(\tilde{m}_{P}\right)^{2}\right\}}: \lambda>0\right\}
$$




\section{Comparison}

Using the results in the previous subsections, we are now able to prove our first main result concerning mutual fund portfolio efficiency.

\section{Theorem 1}

A fund portfolio which is efficient for an informed fund investor is never efficient for an uninformed fund investor.

Proof of Theorem $\prod_{1}$ To prove Theorem 1 we consider a portfolio, $w_{I}^{*}\left(\tilde{m}_{P}, \bar{\lambda}\right)$, which is optimal for an informed investor with risk aversion parameter $\bar{\lambda}$. We then check whether this portfolio also belongs to the set of portfolios, $w_{U}^{*}\left(\tilde{m}_{P}, \lambda\right)$, which are efficient for uninformed investors. Therefore, we keep the parameter $\bar{\lambda}$ in $(16)$ fix, equate the two optimal trading rules $w_{I}^{*}\left(\tilde{m}_{P}, \bar{\lambda}\right)=w_{U}^{*}\left(\tilde{m}_{P}, \lambda\right)$ according to (16) and (19), and solve for $\lambda$ :

$$
\lambda=\bar{\lambda} \cdot \frac{\left(\operatorname{var}\left(\tilde{R}_{E}\right)-\mathrm{E}\left[\tilde{R}_{E}\right]^{2}\right)+\frac{2 \mathrm{E}\left[\tilde{R}_{E}\right]^{3}}{\left(\mathrm{E}\left[\tilde{R}_{E}\right]+\tilde{m}_{P}\right)}}{\operatorname{var}\left(\tilde{R}_{E}\right)+\mathrm{E}\left[\tilde{R}_{E}\right]^{2}+2 \operatorname{var}\left(\tilde{m}_{P}\right)+\frac{2 \operatorname{var}\left(\tilde{m}_{P}\right)^{2}}{\operatorname{var}\left(\tilde{\gamma}_{P}\right)}} .
$$

(21) shows the risk aversion coefficient $\lambda$ which an uninformed investor had to have so that $w_{I}^{*}\left(\tilde{m}_{P}, \bar{\lambda}\right)$ were also her optimal trading rule. Note that the numerator in 21 depends on the signal $\tilde{m}_{P}$. It follows that there does not exist a risk aversion coefficient $\lambda$ that satisfies (21) in every state of the world. Varying $\bar{\lambda}>0$ in (21) shows that such a risk aversion parameter $\lambda$ never exists. Therefore, a trading rule that is optimal for an informed investor is never efficient for uninformed investors, and vice versa. This proves Theorem 1 .

This theorem has strong implications for delegated portfolio management. A fund manager has to trade not only based on her own information, but also has to take into account what 
the fund investor knows. The information of the fund investor matters even when fund managers have superior information. In Appendix C we prove that it might even be the case that uninformed fund investors are better off by following a simple benchmark strategy than by giving the money to a better informed fund manager who ignores the information asymmetry between manager and investor.

\section{Mutual Fund Performance}

We are now interested in the implications of our results in Section [II] on mutual fund performance measurement. We evaluate performance measures by means of their unbiasedness in the sense of Dybvig and Ross (1985). We will show that both, the measure suggested by Jensen (1968),

$$
J_{P}=\mathrm{E}\left[\tilde{R}_{P}^{T}\right]-\left(\beta_{P}-\mathrm{E}\left[\tilde{w}_{P}\right]\right) \mathrm{E}\left[\tilde{R}_{E}\right]
$$

and the market timing measure suggested by Grinblatt and Titman (1989),

$$
J_{P}^{\text {Timing }}=E\left[\tilde{R}_{P}^{T}\right]
$$

are unbiased measures of the performance of market timers. However, they have to be applied by investors with different information sets. The Jensen measure (22) is unbiased if investors are uninformed, whereas the measure of Grinblatt and Titman is unbiased for investors being informed. 


\section{A. Informed Investors}

We focus first on a fund investor who knows the fund holdings. For this investor, the systematic fund risk of a pure market timing fund is equal to $\mathrm{E}\left[\tilde{w}_{P}\right]$, the fraction of wealth the investor expects the fund manager to invest in the benchmark asset [e.g Jensen (1972), Grinblatt and Titman (1989), (1995)]. Substituting $\mathrm{E}\left[\tilde{w}_{P}\right]$ for $\beta_{P}$ into 22 shows that the Jensen measure for informed investors simplifies to:

$$
J_{P}^{\text {Informed }}=\mathrm{E}\left[\tilde{R}_{P}^{T}\right]
$$

Note that this measure corresponds not only to the market timing measure 23 ) of Grinblatt and Titman (1989), but also to the holdings based measure of Grinblatt and Titman (1993) for a pure market timer, $\operatorname{cov}\left(\tilde{w}_{P}, \tilde{R}_{E}\right)$ :

$$
J_{P}^{\text {Informed }}=\mathrm{E}\left[\tilde{R}_{P}^{T}\right]=\mathrm{E}\left[\left(\tilde{w}_{P}-\mathrm{E}\left[\tilde{w}_{P}\right]\right) \tilde{R}_{E}\right]=\operatorname{cov}\left(\tilde{w}_{P}, \tilde{R}_{E}\right)
$$

We now show that the Jensen measure (24) correctly classifies market timing funds, given that fund investors are informed.

\section{Theorem 2}

The performance measure 240 is an unbiased performance measure in the notion of Dybvig and Ross (1985) for a pure market timing fund, if fund investors know the fund holdings:

(i) It is zero for uninformed market timers,

(ii) it is positive for informed market timers who choose the optimal trading rule (16), and

(iii) for those market timers it is the larger the better the information of the fund manager is. 


\section{Proof of Theorem 2}

If the fund manager is uninformed, she chooses her holdings independent from benchmark return, i.e. $\operatorname{cov}\left(\tilde{w}_{P}, \tilde{R}_{E}\right)=0$. From (25) it follows immediately that the Jensen measure of informed investors is equal to zero in this case. This proves statement (i).

If the fund manager behaves optimally with respect to the expected utility of her clients, her trading rule is (16). Substituting (16) into (25) we get:

$$
\begin{aligned}
J_{P}^{\text {Informed }} & =\mathrm{E}\left[\left(w_{I}^{*}\left(\tilde{m}_{P}\right)-\mathrm{E}\left[w_{I}^{*}\left(\tilde{m}_{P}\right)\right]\right) \tilde{R}_{E}\right] \\
& =\mathrm{E}\left[\left(\frac{\mathrm{E}\left[\tilde{R}_{E}\right]+\tilde{m}_{P}}{\lambda \operatorname{var}\left(\tilde{\gamma}_{P}\right)}-\frac{\mathrm{E}\left[\tilde{R}_{E}\right]}{\lambda \operatorname{var}\left(\tilde{\gamma}_{P}\right)}\right)\left(\mathrm{E}\left[\tilde{R}_{E}\right]+\tilde{m}_{P}+\tilde{\gamma}_{P}\right)\right] \\
& =\frac{\operatorname{var}\left(\tilde{m}_{P}\right)}{\lambda \operatorname{var}\left(\tilde{\gamma}_{P}\right)}
\end{aligned}
$$

(26) is strictly positive provided that the fund manager has private information, i.e. $\operatorname{var}\left(\tilde{m}_{P}\right)>$ 0. This proves statement (ii).

The amount of private information is determined by the variability of the market timing signal, $\operatorname{var}\left(\tilde{m}_{P}\right)$. The larger $\operatorname{var}\left(\tilde{m}_{P}\right)$, the better is the information of the fund manager. Since $\operatorname{var}\left(\tilde{R}_{E}\right)=\operatorname{var}\left(\tilde{m}_{P}\right)+\operatorname{var}\left(\tilde{\gamma}_{P}\right)$, we can rewrite 26 as:

$$
J_{P}^{\text {Informed }}=\frac{\operatorname{var}\left(\tilde{m}_{P}\right)}{\lambda\left[\operatorname{var}\left(\tilde{R}_{E}\right)-\operatorname{var}\left(\tilde{m}_{P}\right)\right]}
$$

It is easily verified that 277 increases monotonically in $\operatorname{var}\left(\tilde{m}_{P}\right)$. This proves statement (iii) of Theorem 2 .

Theorem 2 shows that the Jensen measure (24) is a suitable performance measure when used by informed investors for the performance evaluation of market timers. It assigns positive performance only to informed market timers and it allows for fund rankings which mirror the grade of managerial information provided fund managers choose the optimal trading rule (16). 


\section{B. Uninformed Investors}

We now turn to the case that fund investors do not have access to the fund holdings. Since uninformed fund investors cannot identify the average benchmark exposure $\mathrm{E}\left[\tilde{w}_{P}\right]$, they have to use $\beta_{P}$ given by (3) as systematic fund risk, instead. Theorem 3 summarizes our second main result: The Jensen measure (22) is unbiased if fund investors are uninformed.

\section{Theorem 3}

The performance measure 22 is an unbiased performance measure in the notion of Dybvig and Ross (1985) for a pure market timing fund manager, if fund investors do not know the fund holdings:

(i) It is zero for uninformed market timers,

(ii) it is positive for informed market timers who choose the optimal trading rule (19), and

(iii) for those market timers it is the larger the better the information of the fund manager is, provided that $\operatorname{var}\left(\tilde{R}_{E}\right) \neq \mathrm{E}\left[\tilde{R}_{E}\right]^{2}$.

\section{Proof of Theorem 3}

Using the linearity of the managerial trading rule, the expected fund return and the fund beta in (2) are readily verified to be $\mathrm{E}\left[\tilde{R}_{P}\right]=a_{U, P}^{*} \mathrm{E}\left[\tilde{R}_{E}\right]+b_{U, P}^{*} \operatorname{var}\left(\tilde{m}_{P}\right)$ and $\beta_{P}=a_{U, P}^{*}+$ $b_{U, P}^{*}\left\{\mathrm{E}\left[\tilde{R}_{E}\right] \operatorname{var}\left(\tilde{m}_{P}\right)\right\} / \operatorname{var}\left(\tilde{\gamma}_{P}\right)$, respectively. Inserting $b_{U, P}^{*}$ derived in Eq. B5 in Appendix $B$, the closed form solution for the Jensen measure (22) is:

$$
\begin{aligned}
J_{P} & =b_{U, P}^{*}\left(1-\frac{\mathrm{E}\left[\tilde{R}_{E}\right]^{2}}{\operatorname{var}\left(\tilde{R}_{E}\right)}\right) \operatorname{var}\left(\tilde{m}_{P}\right) \\
& =\frac{\operatorname{var}\left(\tilde{m}_{P}\right)}{\lambda \operatorname{var}\left(\tilde{R}_{E}\right)} \cdot \frac{\left(\operatorname{var}\left(\tilde{R}_{E}\right)-\mathrm{E}\left[\tilde{R}_{E}\right]^{2}\right)^{2}}{\operatorname{var}\left(\tilde{\gamma}_{P}\right)\left(\operatorname{var}\left(\tilde{R}_{E}\right)+\mathrm{E}\left[\tilde{R}_{E}\right]^{2}+2 \operatorname{var}\left(\tilde{m}_{P}\right)\right)+2 \operatorname{var}\left(\tilde{m}_{P}\right)^{2}}
\end{aligned}
$$


From (28) it follows immediately that the Jensen measure is equal to zero if the fund manager does not get a signal, i.e. $m_{P} \equiv 0$ and consequently var $\left(m_{P}\right)=0$. This proves statement (i).

If the fund manager has private information, we have $\operatorname{var}\left(\tilde{m}_{P}\right)>0$. Since 29) only contains variances and squared terms, the Jensen measure is strictly positive in this case, given $\operatorname{var}\left(\tilde{R}_{E}\right) \neq \mathrm{E}\left[\tilde{R}_{E}\right]^{2}$. This proves statement (ii).

The grade of managerial skill is determined by the size of $\operatorname{var}\left(\tilde{m}_{P}\right)$. Since $\operatorname{var}\left(\tilde{R}_{E}\right)=$ $\operatorname{var}\left(\tilde{m}_{P}\right)+\operatorname{var}\left(\tilde{\gamma}_{P}\right)$, we rewrite the Jensen measure (29) as

$$
J_{P}=\frac{\left(\operatorname{var}\left(\tilde{R}_{E}\right)-\mathrm{E}\left[\tilde{R}_{E}\right]^{2}\right)^{2}}{\lambda \operatorname{var}\left(\tilde{R}_{E}\right)\left[\left(\operatorname{var}\left(\tilde{R}_{E}\right)-\mathrm{E}\left[\tilde{R}_{E}\right]^{2}\right)+\frac{\operatorname{var}\left(\tilde{R}_{E}\right)}{\operatorname{var}\left(\tilde{m}_{P}\right)} \cdot\left(\operatorname{var}\left(\tilde{R}_{E}\right)+\mathrm{E}\left[\tilde{R}_{E}\right]^{2}\right)\right]}
$$

It is easily verified that 30 increases monotonically in $\operatorname{var}\left(\tilde{m}_{P}\right)$, for $\operatorname{var}\left(\tilde{R}_{E}\right) \neq \mathrm{E}\left[\tilde{R}_{E}\right]^{2}$. This proves statement (iii) of Theorem 3 .

Theorem 3 shows that superior market timing information makes mutual fund managers plot above the SML, given they choose the optimal trading rule (19). An informed market timer plots below the SML only if she chooses a wrong trading strategy. A negative Jensen alpha may occur if the fund manager uses the trading rule (16) which would be optimal if fund investors were informed, but fund investors in fact are uninformed. Then, the Jensen measure correctly assigns a bad performance to this fund manager, not because she is uninformed, but because she used the wrong trading strategy.

Our results seem to contradict previous findings of Dybvig and Ross (1985), Admati and Ross (1985), and Grinblatt and Titman (1989) in this respect. They show that the Jensen measure (22) of informed market timers might exhibit a negative alpha and attribute this to a biased performance estimate. However, they derive their result using a trading strategy which 
is optimal given the private information of the fund manager. This strategy is the same as the optimal strategy for informed investors (16). As shown by Theorem 1, such a trading strategy is not optimal for uninformed fund investors $3^{3}$ Since the Jensen measure $(22)$ is an external performance measure, i.e. based on the assumption that investors cannot observe fund holdings, Dybvig and Ross (1985), Admati and Ross (1985), and Grinblatt and Titman (1989) all derive their results based on a erroneous trading strategy. Therefore, a negative alpha of informed market timers does not result from a bias-in-beta, but from an erroneous trading rule of the fund manager.

\section{Comparison}

As shown in Subsections $A$ and $B$, fund investors differing with respect to their information have to use different performance measures. They assign different Jensen alphas to the same fund. We now analyze the reason for this to appear.

$$
\Delta J_{P}=J_{P}^{\text {Informed }}-J_{P}^{\text {Uninformed }}=\left(\beta_{P}-\mathrm{E}\left[\tilde{w}_{P}\right]\right) \mathrm{E}\left[\tilde{R}_{E}\right]
$$

The difference in (31) is equal to the bias-in-beta term in Grinblatt and Titman (1989). In the remainder we will argue that this term does not reflect a bias in beta, but an additional risk premium for uninformed fund investors. For this purpose we decompose the systematic fund risk borne by uninformed fund investors.

\section{Corrolary 1}

The systematic fund risk consists of two components if fund investors are uninformed:

\footnotetext{
${ }^{3}$ It would only be optimal if the fund investor observed the signal of the fund manager, or, at least knew that the manager is informed. This is the implicit assumption taken by Dybvig and Ross (1985). However, investors are then no longer uninformed.
} 
(i) The systematic risk the investor would bear if she were informed, and

(ii) additional systematic risk reflecting her uncertainty about whether the fund manager is informed.

\section{Proof of Corrolary 1}

First, we expand the systematic fund risk of uninformed investors (3) by the average benchmark holding of the fund, $\mathrm{E}\left[\tilde{w}_{P}\right]$ :

$$
\beta_{P}=\mathrm{E}\left[\tilde{w}_{P}\right]+\frac{\operatorname{cov}\left(\left(\tilde{w}_{P}-\mathrm{E}\left[\tilde{w}_{P}\right]\right) \tilde{R}_{E}, \tilde{R}_{E}\right)}{\operatorname{var}\left(\tilde{R}_{E}\right)}
$$

Since informed investors observe fund holdings, $\mathrm{E}\left[\tilde{w}_{P}\right]$ is their systematic risk (see the arguments in Subsection A). Therefore, $\mathrm{E}\left[\tilde{w}_{P}\right]$ quantifies the systematic risk the investor would bear if she observed the fund holdings. In Appendix $D$ we show that (32) can be rewritten as:

$$
\beta_{P}=\mathrm{E}\left[\tilde{w}_{P}\right]+\mathrm{E}\left[\frac{\partial \tilde{w}_{P}}{\partial m_{P}}\right] \mathrm{E}\left[\tilde{R}_{E}\right]+\mathrm{E}\left[\frac{\partial^{2} \tilde{w}_{P}}{\partial m_{P}^{2}}\right] \operatorname{var}\left(\tilde{R}_{E}\right)
$$

Since the fund manager is a market timer, the sum of the second and third component on the RHS of (33) is generally different from zero, and $\beta_{P} \neq \mathrm{E}\left[\tilde{w}_{P}\right]$.

The additional systematic risk always occurs when fund investors are uninformed. Using (5) and (32) we rewrite the Jensen measure (22) as:

$$
J_{P}=\mathrm{E}\left[\tilde{R}_{P}^{T}\right]-\frac{\operatorname{cov}\left(\tilde{R}_{P}^{T}, \tilde{R}_{E}\right)}{\operatorname{var}\left(\tilde{R}_{E}\right)} \mathrm{E}\left[\tilde{R}_{E}\right]
$$

(34) highlights that market timing has two effects on mutual fund performance, given that investors are uninformed: First, market timing increases the expected fund return by $\mathrm{E}\left[\tilde{R}_{P}^{T}\right]$. Second, it increases the systematic risk for the uninformed investor by $\operatorname{cov}\left(\tilde{R}_{P}^{T}, \tilde{R}_{E}\right) / \operatorname{var}\left(\tilde{R}_{E}\right)$. 
Comparing (23) and (34) shows that the additional systematic risk occurs only for uninformed investors. According to 32 this risk results from the fact that uninformed investors cannot identify the dynamics of the fund holdings. Therefore, she cannot observe whether the fund manager has a private signal. In contrast, if investors are informed no management risk shows up. Informed investors can immediately infer the manager's private signal by observing the fund holdings. Thus, the performance difference (31) between informed and uninformed investors does not result from a bias in beta. It is a risk premium due to the uncertainty of the uninformed investor about the trading strategy of the fund manager $4_{4}^{4}$

\section{Conclusion}

Whether the classical performance measures based on the CAPM [e.g. Jensen (1968), Sharpe (1966)] on theoretical grounds correctly identify successful market timing as superior performance has been the focus of a good deal of academic controversy. Successively, Jensen (1972), Admati and Ross (1985), Dybvig and Ross (1985), and Grinblatt and Titman (1989), (1995) have pointed out that classical performance measures based on the CAPM provide upwards biased estimates of fund risk and, therefore, downwards biased estimates of fund performance for successful market timers.

In this paper we have questioned this common view. We have presented a model of delegated portfolio management under asymmetric information. We have showed that two investors, one observing the fund holdings and the other not, bear different amounts of risk investing in the same fund. Therefore, the optimal trading strategy and, finally, the performance

\footnotetext{
${ }^{4} \mathrm{~A}$ related intuition is that if the fund manager were uninformed, she had to invest a fraction $\beta_{P}$ of the fund portfolio in the benchmark asset in order to generate an expected fund return of $\mathrm{E}\left[\tilde{R}_{P}\right]$. Since we assume the market share of informed fund managers to be negligible, uninformed investors ex-ante rationally expect the fund manager to have invested this fraction $\beta_{P} \neq \mathrm{E}\left[\tilde{w}_{P}\right]$ in the benchmark asset.
} 
of a fund depends on what investors know about the fund holdings. We then have proved that the Jensen alpha for uninformed fund investors satisfies all conditions for unbiasedness, which we have taken from Dybvig and Ross (1985): Alpha assigns a positive performance to market timers who have superior private information, and only to those. And provided optimal behaviour of fund managers, it is the larger the better informed a market timer is.

The results presented in the paper provide interesting insides into mutual fund management. Fund managers have to take into account if their investors observe the fund holdings when deciding on the fund composition. Moreover, investment companies can increase the attraction of successful mutual funds by providing sufficient fund holdings information to their clients. And finally, uninformed fund investors do not unintentionally discriminate market timing funds when using the classical CAPM based performance measures as, for example, Jensen alpha. 


\section{Appendix A}

In this Appendix we prove Eqs. 14 and 15 . Using her fund holdings information the investor makes the following linear regression of the benchmark excess return, $R_{E}$, on the fund holdings, $w_{I}$ :

$$
\tilde{R}_{E}=\delta_{0}+\delta_{1} \tilde{w}_{I}+\tilde{\varepsilon}
$$

Since the managerial trading rule is linear, $\tilde{\varepsilon}$ in (A1) is a standard error term. Using the conditional expectation of $R_{E}$ given the observation of $w_{I}$ in $\mathrm{A} 1 \mathrm{l}$ and the linearity of the managerial trading rule, $w_{I}\left(\tilde{m}_{P}\right)=a_{I, P}+b_{I, P} \tilde{m}_{P}$, the benchmark return inference conditional in $w_{I}$ is:

$$
\begin{aligned}
\mathrm{E}\left[\tilde{R}_{E} \mid w_{I}\right] & =\mathrm{E}\left[\tilde{R}_{E}\right]+\delta_{1}\left(w_{I}-\mathrm{E}\left[\tilde{w}_{I}\right]\right) \\
& =\mathrm{E}\left[\tilde{R}_{E}\right]+\frac{1}{b_{I, P}}\left(a_{I, P}+b_{I, P} \tilde{m}_{P}-a_{I, P}\right) \\
& =\mathrm{E}\left[\tilde{R}_{E}\right]+\tilde{m}_{P}
\end{aligned}
$$

The inference of the benchmark return variance conditional on $w_{I}$ is given by the residual variance of the linear regression in (A1),

$$
\operatorname{var}\left(\tilde{R}_{E} \mid w_{I}\right)=\left[1-R_{I}^{2}\right] \operatorname{var}\left(\tilde{R}_{E}\right)
$$

where $R_{I}^{2}$ is the $R$-squared of the regression $\mathrm{A} 1$. Using the definition of $R$-squared, the linearity of the managerial trading rule, and Equation (8), the $R$-squared in (A3) simplifies to:

$$
\begin{aligned}
R_{I}^{2} & =\frac{\operatorname{cov}\left(b_{I, P} \tilde{m}_{P}, \tilde{m}_{P}+\tilde{\gamma}_{P}\right)^{2}}{\operatorname{var}\left(b_{I, P} \tilde{m}_{P}\right) \operatorname{var}\left(\tilde{R}_{E}\right)} \\
& =\frac{b_{I, P}^{2} \operatorname{var}\left(\tilde{m}_{P}\right)^{2}}{b_{I, P}^{2} \operatorname{var}\left(\tilde{m}_{P}\right) \operatorname{var}\left(\tilde{R}_{E}\right)} \\
& =\frac{\operatorname{var}\left(\tilde{m}_{P}\right)}{\operatorname{var}\left(\tilde{R}_{E}\right)}
\end{aligned}
$$


Substituting $\mathrm{A} 4 \mathrm{~S}$ in $\mathrm{A} 3 \mathrm{~s}$, the inference of the benchmark return variance of informed fund investors is:

$$
\begin{aligned}
\operatorname{var}\left(\tilde{R}_{E} \mid w_{I}\right) & =\left[1-\frac{\operatorname{var}\left(\tilde{m}_{P}\right)}{\operatorname{var}\left(\tilde{R}_{E}\right.}\right] \operatorname{var}\left(\tilde{R}_{E}\right) \\
& =\operatorname{var}\left(\tilde{\gamma}_{P}\right)
\end{aligned}
$$

\section{Appendix B}

In this Appendix we prove Eq. 19 Replacing the fund weights $w_{U}\left(\tilde{m}_{P}\right)$ by the linear trading strategy $a_{U, P}+b_{U, P} \tilde{m}_{P}$ and subsequently using the independence of $\tilde{m}_{P}$ and $\tilde{\gamma}_{P}$, we rewrite the expected utility in (18) as:

$$
\begin{aligned}
\Phi_{U}= & a_{U, P} \mathrm{E}\left[\tilde{R}_{E}\right]+b_{U, P} \operatorname{var}\left(\tilde{m}_{P}\right) \\
& -\frac{\lambda}{2}\left\{\left(a_{U, P}^{2}+b_{U, P}^{2} \operatorname{var}\left(\tilde{m}_{P}\right)\right) \operatorname{var}\left(\tilde{\gamma}_{P}\right)+\left(a_{U, P}+b_{U, P} \mathrm{E}\left[\tilde{R}_{E}\right]\right)^{2} \operatorname{var}\left(\tilde{m}_{P}\right)+2 b_{U, P}^{2} \operatorname{var}\left(\tilde{m}_{P}\right)^{2}\right\}
\end{aligned}
$$

The first order conditions of $(\mathrm{B} 1)$ are:

$$
\begin{array}{r}
\frac{\partial \Phi_{U}}{\partial a_{U, P}}=\mathrm{E}\left[\tilde{R}_{E}\right]-\lambda\left\{a_{U, P} \operatorname{var}\left(\gamma_{P}\right)+\left(a_{U, P}+b_{U, P} \mathrm{E}\left[\tilde{R}_{E}\right) \operatorname{var}\left(\tilde{m}_{P}\right)\right\}=0\right. \\
\frac{\partial \Phi_{U}}{\partial b_{U, P}}=\operatorname{var}\left(\tilde{m}_{P}\right)\left\{1-\lambda\left[b_{U, P} \operatorname{var}\left(\tilde{\gamma}_{P}\right)+\left(a_{U, P}+b_{U, P} \mathrm{E}\left[\tilde{R}_{E}\right]\right) \mathrm{E}\left[\tilde{R}_{E}\right]+2 b_{U, P} \operatorname{var}\left(\tilde{m}_{P}\right)\right]\right\}=0
\end{array}
$$

Solving (B2) and (B3) for $a_{U, P}$ and $b_{U, P}$ and using $\operatorname{var}\left(\tilde{R}_{E}\right)=\operatorname{var}\left(\tilde{m}_{P}\right)+\operatorname{var}\left(\tilde{\gamma}_{P}\right)$, the parameters of the optimal trading strategy are

$$
\begin{aligned}
& a_{U, P}^{*}=\frac{1}{\lambda} \cdot \frac{\mathrm{E}\left[\tilde{R}_{E}\right]\left(\operatorname{var}\left(\tilde{R}_{E}\right)+\mathrm{E}\left[\tilde{R}_{E}\right]^{2}\right)}{\operatorname{var}\left(\tilde{\gamma}_{P}\right)\left(\operatorname{var}\left(\tilde{R}_{E}\right)+\mathrm{E}\left[\tilde{R}_{E}\right]^{2}+2 \operatorname{var}\left(\tilde{m}_{P}\right)\right)+2 \operatorname{var}\left(\tilde{m}_{P}\right)^{2}} \\
& b_{U, P}^{*}=\frac{1}{\lambda} \cdot \frac{\operatorname{var}\left(\tilde{R}_{E}\right)-\mathrm{E}\left[\tilde{R}_{E}\right]^{2}}{\operatorname{var}\left(\tilde{\gamma}_{P}\right)\left(\operatorname{var}\left(\tilde{R}_{E}\right)+\mathrm{E}\left[\tilde{R}_{E}\right]^{2}+2 \operatorname{var}\left(\tilde{m}_{P}\right)\right)+2 \operatorname{var}\left(\tilde{m}_{P}\right)^{2}}
\end{aligned}
$$


Substituting $a_{U, P}^{*}$ and $b_{U, P}^{*}$ according to $(\widehat{\mathrm{B} 4})$ and $(\overline{\mathrm{B} 5})$ into $w_{U}\left(\tilde{m}_{P}\right)=a_{U, P}^{*}+b_{U, P}^{*} \tilde{m}_{P}$ yields Equation (19).

\section{Appendix C}

Since the fund manager in this case does not act optimally in the interests of her clients, we first determine the optimal proportion of wealth $\alpha$ for uninformed investors to invest in the fund. Substituting a multiple $\alpha$ of the managerial trading rule $(16)$ into $(18)$, the resulting problem is to choose $\alpha$ so as to maximize:

$$
\begin{aligned}
\Phi_{U}\left(\alpha w_{I}\left(\tilde{m}_{P}\right)\right)= & \alpha\left[\frac{\mathrm{E}\left[\tilde{R}_{E}\right]^{2}+\operatorname{var}\left(\tilde{m}_{P}\right)}{\lambda \operatorname{var}\left(\tilde{\gamma}_{P}\right)}\right] \\
& -\frac{\lambda}{2} \alpha^{2}\left[\frac{\operatorname{var}\left(\tilde{\gamma}_{P}\right)\left[\mathrm{E}\left[\tilde{R}_{E}\right]^{2}+\operatorname{var}\left(\tilde{m}_{P}\right)\right]+2 \operatorname{var}\left(\tilde{m}_{P}\right)\left[2 \mathrm{E}\left[\tilde{R}_{E}\right]^{2}+\operatorname{var}\left(\tilde{m}_{P}\right)\right]}{\lambda^{2} \operatorname{var}\left(\tilde{\gamma}_{P}\right)^{2}}\right]
\end{aligned}
$$

Solving (C1), the optimal proportion of wealth to invest in the fund is:

$$
\alpha^{*}=\frac{\operatorname{var}\left(\tilde{\gamma}_{P}\right)\left[\mathrm{E}\left[\tilde{R}_{E}\right]^{2}+\operatorname{var}\left(\tilde{m}_{P}\right)\right]}{\operatorname{var}\left(\tilde{\gamma}_{P}\right)\left[\mathrm{E}\left[\tilde{R}_{E}\right]^{2}+\operatorname{var}\left(\tilde{m}_{P}\right)\right]+2 \operatorname{var}\left(\tilde{m}_{P}\right)\left[2 \mathrm{E}\left[\tilde{R}_{E}\right]^{2}+\operatorname{var}\left(\tilde{m}_{P}\right)\right]}
$$

Substituting $\alpha^{*}$ according to $(\mathrm{C} 2)$ back into $(\mathrm{C} 1)$, we get the maximal utility of uninformed investors from a fund investment:

$$
\Phi_{U}\left(\alpha^{*} w_{I}\left(\tilde{m}_{P}\right)\right)=\frac{\left[\mathrm{E}\left[\tilde{R}_{E}\right]^{2}+\operatorname{var}\left(\tilde{m}_{P}\right)\right]^{2}}{2 \lambda\left[\operatorname{var}\left(\tilde{\gamma}_{P}\right)\left[\mathrm{E}\left[\tilde{R}_{E}\right]^{2}+\operatorname{var}\left(\tilde{m}_{P}\right)\right]+2 \operatorname{var}\left(\tilde{m}_{P}\right)\left[2 \mathrm{E}\left[\tilde{R}_{E}\right]^{2}+\operatorname{var}\left(\tilde{m}_{P}\right)\right]\right]}
$$

Using (C3) and the expression for the expected utility from a passive investment into the benchmark asset, $\mathrm{E}\left[\tilde{R}_{E}\right] /\left\{2 \lambda\left[\operatorname{var}\left(\tilde{m}_{P}\right)+\operatorname{var}\left(\tilde{\gamma}_{P}\right)\right]\right\}$, the difference in expected utility is:

$$
\Delta\left(\Phi_{U}\right)=\frac{\operatorname{var}\left(\tilde{m}_{P}\right)\left[\left(\operatorname{var}\left(\tilde{R}_{E}\right)-\mathrm{E}\left[\tilde{R}_{E}\right]^{2}\right)\left(\mathrm{E}\left[\tilde{R}_{E}\right]^{2}+\operatorname{var}\left(\tilde{m}_{P}\right)\right)-2 \mathrm{E}\left[\tilde{R}_{E}\right]^{4}\right]}{2 \lambda \operatorname{var}\left(\tilde{R}_{E}\right)\left[\operatorname{var}\left(\tilde{\gamma}_{P}\right)\left(\mathrm{E}\left[\tilde{R}_{E}\right]^{2}+\operatorname{var}\left(\tilde{m}_{P}\right)\right)+2 \operatorname{var}\left(\tilde{m}_{P}\right)\left(2 \mathrm{E}\left[\tilde{R}_{E}\right]^{2}+\operatorname{var}\left(\tilde{m}_{P}\right)\right)\right]}
$$


This difference is negative provided that $\operatorname{var}\left(\tilde{R}_{E}\right)<\mathrm{E}\left[\tilde{R}_{E}\right]^{2}$. It is also negative for some parameter constellations where $\operatorname{var}\left(\tilde{R}_{E}\right)>\mathrm{E}\left[\tilde{R}_{E}\right]^{2}$, depending on the grade of managerial skills, $\operatorname{var}\left(\tilde{m}_{P}\right)$. Only if $\operatorname{var}\left(\tilde{R}_{E}\right) \geq 3 \mathrm{E}\left[\tilde{R}_{E}\right]^{2}$, we have that $\Delta\left(\Phi_{U}\right)>0$ for every $\operatorname{var}\left(\tilde{m}_{P}\right)>0$.

\section{Appendix D}

We prove Eq. 33 in two steps: First, we determine $\operatorname{cov}\left(\tilde{w}_{P} \tilde{R}_{E}, \tilde{R}_{E}\right)$ and second we use these results to verify (33). Central to our proof is a mathematical property of the covariance operator often referred to as Stein's Lemma [see e.g. Losq and Chateau (1982)].

\section{Lemma 1}

Suppose $f(X)$ is a $N$-dimensional continuously differentiable function, $f: \mathbb{R}^{N} \mapsto \mathbb{R}, X$ is a $N$-dimensional multivariate normally distributed random vector, and $Y$ is a normally distributed random variable, then

$$
\operatorname{cov}(f(X), Y)=\mathrm{E}\left[\frac{\partial f(X)}{\partial X}\right]^{\prime} \operatorname{cov}(X, Y)
$$

Here $\frac{\partial f(X)}{\partial X}$ denotes the $N$-vector of the derivatives of $f(X)$ with respect to the $X_{i}, i=1, \ldots, N$, and $\operatorname{cov}(X, Y)$ is the $N$-vector of the covariances, $\operatorname{cov}\left(X_{i}, Y\right), i=1, \ldots, N$.

From Lemma $1, \operatorname{cov}\left(\tilde{w}_{P} \tilde{R}_{E}, \tilde{R}_{E}\right)$ can be decomposed into

$$
\operatorname{cov}\left(\tilde{w}_{P} \tilde{R}_{E}, \tilde{R}_{E}\right)=\mathrm{E}\left[\frac{\partial\left(\tilde{w}_{P} \tilde{R}_{E}\right)}{\partial m_{P}}\right] \operatorname{var}\left(\tilde{R}_{E}\right)
$$


where we have used $\tilde{R}_{E}=\tilde{m}_{P}+\tilde{\gamma}_{P}$ and, consequently, $\partial m_{P} / \partial R_{E}=1$. The derivative in the expectation operator on the right hand side (RHS) of $(\mathrm{D} 2)$ can be written as $w_{P}+\frac{\partial w_{P}}{\partial m_{P}} R_{E}$, and using some covariance algebra, (D2) becomes

$$
\operatorname{cov}\left(\tilde{w}_{P} \tilde{R}_{E}, \tilde{R}_{E}\right)=\left\{\mathrm{E}\left[\tilde{w}_{P}\right]+\mathrm{E}\left[\frac{\partial \tilde{w}_{P}}{\partial m_{P}}\right] \mathrm{E}\left[\tilde{R}_{E}\right]+\operatorname{cov}\left(\left(\frac{\partial \tilde{w}_{P}}{\partial m_{P}}\right), \tilde{R}_{E}\right)\right\} \operatorname{var}\left(\tilde{R}_{E}\right)
$$

Applying Stein's Lemma again to covariance on the RHS of (D3), (D3) simplifies to

$$
\operatorname{cov}\left(\tilde{w}_{P} \tilde{R}_{E}, \tilde{R}_{E}\right)=\left\{\mathrm{E}\left[\tilde{w}_{P}\right]+\mathrm{E}\left[\frac{\partial \tilde{w}_{P}}{\partial m_{P}}\right] \mathrm{E}\left[\tilde{R}_{E}\right]+\mathrm{E}\left[\frac{\partial^{2} \tilde{w}_{P}}{\partial m_{P}^{2}}\right] \operatorname{var}\left(\tilde{R}_{E}\right)\right\} \operatorname{var}\left(\tilde{R}_{E}\right)
$$

where we have again used $\partial m_{P} / \partial R_{E}=1$. We now verify Eq. 33 with $(\mathrm{D} 4)$. Since $\mathrm{E}\left[\tilde{w}_{P}\right] \operatorname{var}\left(\tilde{R}_{E}\right)=$ $\operatorname{cov}\left(\mathrm{E}\left[\tilde{w}_{P}\right] \tilde{R}_{E}, \tilde{R}_{E}\right)$, we rewrite $\mathrm{D} 4$ as

$$
\frac{\operatorname{cov}\left(\left(\tilde{w}_{P}-\mathrm{E}\left[\tilde{w}_{P}\right]\right) \tilde{R}_{E}, \tilde{R}_{E}\right)}{\operatorname{var}\left(\tilde{R}_{E}\right)}=\mathrm{E}\left[\frac{\partial \tilde{w}_{P}}{\partial m_{P}}\right] \mathrm{E}\left[\tilde{R}_{E}\right]+\mathrm{E}\left[\frac{\partial^{2} \tilde{w}_{P}}{\partial m_{P}^{2}}\right] \operatorname{var}\left(\tilde{R}_{E}\right)
$$

Substituting (D5) into 32 then yields Eq. 33 in the paper. 


\section{References}

Admati, A., and P. Pfleiderer, 1997, "Does It All Add Up? Benchmarks and the Compensation of Active Portfolio Managers," Journal of Business, 70, 323-350.

Admati, A., and S. Ross, 1985, "Measuring Investment Performance in a Rational Expectations Equilibrium Model," Journal of Business, 58, 1-26.

Bollen, N., and J. A. Busse, 2001, "On the Timing Ability of Mutual Fund Managers," Journal of Finance, 56, 1075-1094.

Chance, D. M., and M. L. Hemler, 2001, "The Performance of Professional Market Timers: Daily Evidence from Executed Strategies,” Journal of Financial Economics, 62, 377-411.

Coles, J., J. Suay, and D. Woodbury, 2000, "Fund Advisor Compensation in Closed End Funds," Journal of Finance, 55, 1385-1414.

Daniel, K. D., M. Grinblatt, S. Titman, and R. Wermers, 1997, "Measuring Mutual Fund Performance with Characteristic Based Benchmarks,” Journal of Finance, 52, 1035-1058.

Dybvig, P. H., and S. A. Ross, 1985, “The Analytics of Performance Measurement Using a Security Market Line," Journal of Finance, 40, 401-416.

Grant, D., 1977, "Portfolio Performance and the "Cost" of Timing Decisions," Journal of Finance, 32, 837-846.

Grinblatt, M., and S. Titman, 1989, "Portfolio Performance Evaluation: Old Issues and New Insights," Review of Financial Studies, 2, 393-421.

_ 1993, "Performance Measurement without Benchmarks: An Examination of Mutual Fund Returns," Journal of Business, 66, 47-68.

Gruber, M., 1996, "Another Puzzle: The Growth in Actively Managed Mutual Funds," Journal of Finance, 51, 783-810. 
Ippolito, R., 1989, “Efficiency with Costly Information: A Study of Mutual Fund Performance, 19651984," Quaterly Journal of Economics, 104, 1-23.

— , 1992, "Consumer Reaction to Measures of Poor Quality: Evidence from the Mutual Fund Industry," Journal of Law and Economics, 35, 45-70.

Jensen, M. C., 1968, “The Performance of Mutual Funds in the Period 1945-1964,” Journal of Finance, 23, 389-416.

— , 1972, "Optimal Utilization of Market Forecasts and the Evaluation of Investment Performance," in Mathematical Methods in Investment and Finance, ed. by G. P. Szegö, and K. Shell. Amsterdam, pp. 310-335.

Losq, E., and J. P. D. Chateau, 1982, "A Generalization of the CAPM Based on a Property of the Covariance Operator," Journal of Financial and Quantitative Analysis, 17, 783-797.

Mayers, D., and E. M. Rice, 1979, "Measuring Portfolio Performance and the Empirical Content of Asset Pricing Models," Journal of Financial Economics, 7, 3-28.

Patel, J., R. Zeckhauser, and D. Hendricks, 1990, “Investment Flows and Performance: Evidence from Mutual Funds, Cross-Border Investments, and New Issues," in Japan, Europe and the International Financial Markets: Analytical and Empirical Perspectives, ed. by R. Sato, R. Levich, and R. Ramachandran. New York, pp. 51-72.

Sharpe, W. F., 1966, “Mutual Fund Performance,” Journal of Business, 39, 119-138.

Treynor, J. L., 1965, "How to Rate Management Of Investment Funds," Harvard Business Review, 43, $63-75$.

Wermers, R., 2000, “Mutual Fund Performance: An Empirical Decomposition into Stock-Picking Talent, Style, Transactions Costs, and Expenses," Journal of Finance, 55, 1655-1695. 